\title{
The origin of altruism
}

\section{Unto Others: The Evolution and Psychology of Unselfish Behavior by Elliott Sober and David Sloan Wilson Harvard University Press: 1998. Pp. 394. $\$ 29.95, £ 19.95$}

\section{John Maynard Smith}

It is obvious that the parts of organisms have specific functions. Since Darwin, this has been explained by natural selection, but what is the target of selection? Should individual organisms be thought of as the units of selection, or must one also consider levels above or below the individual, such as groups of individuals, or genes within individuals? In particular, how can one account for altruistic behaviour, by animals and by humans, or supra-individual structures such as termite mounds or human institutions, which have features ensuring their survival?

These are the questions discussed in this book. Readers unfamiliar with evolutionary biology should be warned that these questions have been the topic of long and occasionally acrimonious debates, in which the authors have been active participants. Readers of this review should also be warned that I have also been a participant, often on the other side.

The first half of the book discusses the role of population structure in the evolution of animal behaviour, in particular of altruistic behaviour. Although I have been a participant, I find it quite hard to decide what the current debate is about. Is it about what the world is like, or about the best words to use when we describe it? When I first became interested, back in the 1960s, it seemed fairly clear. Although, most of the time, Darwin regarded the individual organism as the target of selection, it was quite common for biologists to speak as if organs or behaviours existed for the good of the species as a whole.

This view was expressed with particular clarity in Verne Wynne-Edwards' 1962 book Animal Dispersion (Oliver and Boyd), which argued that animals limit their breeding to prevent the population exceeding its food supply. His great merit was to see that, for this to be true, selection must be acting on the population as a whole: species whose members limit their breeding survive, whereas those that do not become extinct. It is not hard to see that this will not work, and that the observed behaviours - such as territorial behaviour — can be explained in other ways. Elliott Sober and David Sloan Wilson would agree, but they would also argue, I think correctly, that if a species is divided into partially isolated groups, each established by a few founders, this will affect the traits that evolve.

So, if the 'old' group selection no longer has supporters, and we agree that group structure is important, what are we arguing about? I think the argument is largely semantic, and could not be settled by observation. Two examples will make this clearer. model, first published in 1975 but still very much part of his thinking. A population is divided into trait groups, and selection acts upon them. The members then disperse and mate randomly, and their offspring come together again in trait groups. There are two kinds of individual: altruists, who benefit (in terms of fitness) each of their fellow group members to a degree $b$, at a cost to themselves $c$; and non-altruists, who do not. If costs and benefits combine additively, and groups are formed randomly, then altruism cannot evolve. But if altruists tend to associate with altruists, and non-altruists with non-altruists, then altruism can evolve. This conclusion is agreed. Sober and Wilson interpret this result as arising from a conflict between withingroup selection (favouring non-altruists) and between-group selection (favouring altruists, if assortment is non-random). But it can also be seen as an example of kin selection, an idea developed by William Hamilton in 1963: the values of $b, c$ and degree of assortment required for altruism follow at once from his famous inequality, $b>r c$, where $r$ is the
First, consider Wilson's 'trait group'

degree of relatedness. So we have a single model, but two ways of analysing it.

More briefly, here is a second example. Evolutionary game theory was first developed to explain the ritualistic nature of animal fights. This had often been explained in terms of the 'good of the species': it seemed desirable to George Price and myself to attempt an explanation in terms of individual selection. Sober and Wilson reconsider this model. They come to exactly the same conclusions that we reached, but argue that it is a case of group selection. Why? Essentially, because it is a model of the interaction of two individuals, and, for them, two individuals constitute a group. They ask: "is it really fair to call a pair of individuals a group, especially if they interact only briefly... never to meet again?" They conclude that it is. In effect, they say that any situation in which fitness is determined by interactions between individuals is a case of group selection.

Does it matter what words we use to describe a model if we agree about its consequences? Perhaps it does. We need formal models, but we also need intuition about why the models give the results they do, and the words used guide our intuitions and tell us what to look for. A group selection

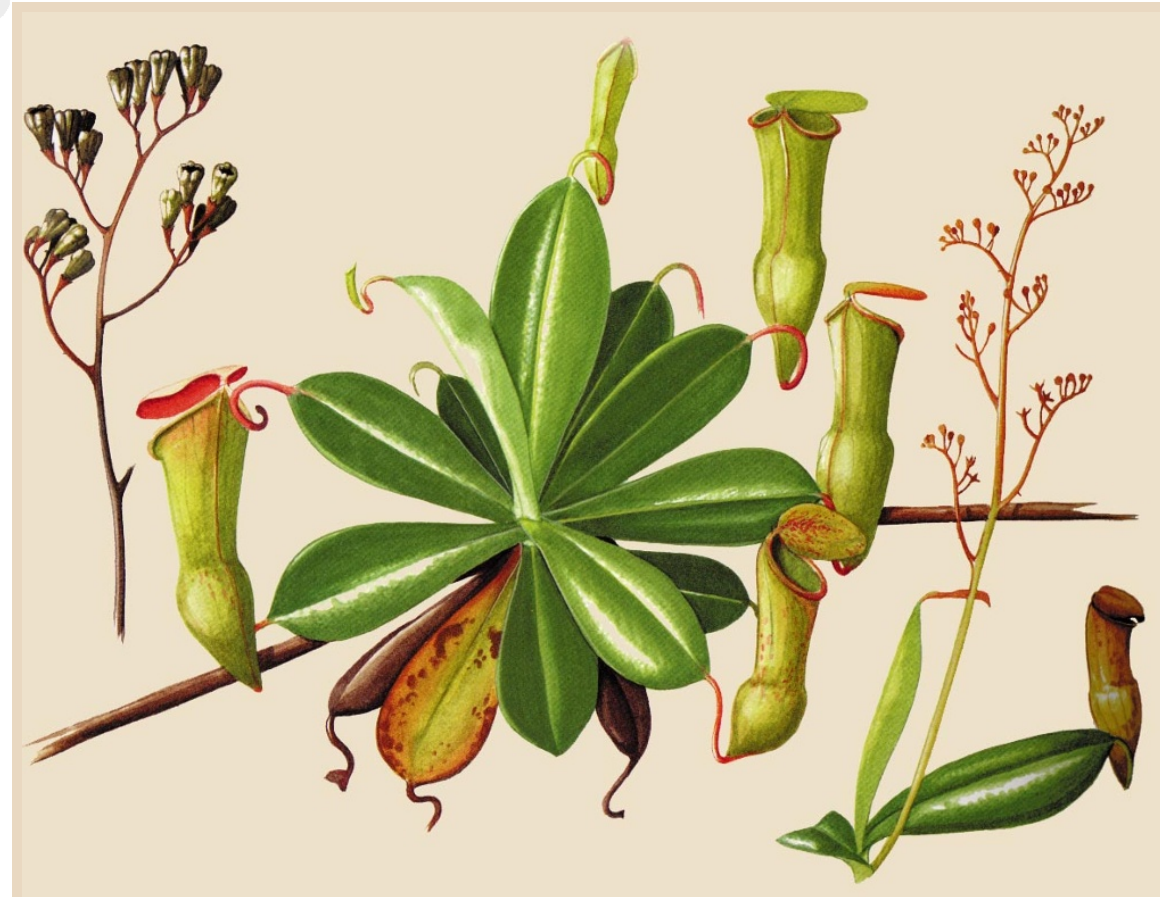

\section{Floral prints}

In 1985, a group of botanists from the University of Oxford studied the flora of the Seychelles. Their artist, Rosemary Wise, spent the next ten years painting these unusual and threatened plants. Her work, including Nepenthes pervillei (above), can be found in A Fragile Eden: Portraits of the Endemic Flowering Plants of the Granitic Seychelles (Princeton University Press, \$75). 
terminology leads us to look for factors causing a difference between variation within and between groups; a kin selection model leads us to look for relatedness; and a game theory model leads us to look for frequency dependence and non-additive fitness interactions.

If this is right, the argument is not about what the world is like, or even about how we should model it (that is, what simplifying assumptions are adequate to explain it), but about what words we should use to explain our model. Is the trait group model an example of group selection or kin selection? Is the game theory model an example of group selection or individual selection?

For several reasons, I think the authors' approach to these questions is confusing. First, they are misleading for historical reasons. For example, when Price and I proposed our model of animal fighting, we were combating the then prevalent idea, supported by no less figures than Julian Huxley and Konrad Lorenz, that ritualized fighting behaviour had evolved for the good of the species. We tried to explain it by individual selection, not between-species selection. Essentially, we were arguing about what is an appropriate model of the world. It is therefore confusing to accept our model, but rename it group selection.

A second reason why the book is confusing is that, although the authors argue for pluralism, they are not themselves pluralists: for them, the only right way to describe a model is in group selection language. Any attempt to calculate the behaviour of a model by estimating the fitness of individuals is condemned as "fallacious averaging" (although Wilson himself carried out just such an averaging process in his original trait group model). It is "fallacious" because it detracts attention from the role of grouplevel processes (which, for them, include all interactions between individuals). The result of this bias is that it gives the impres-

\section{Science book prize}

Jared Diamond, professor of physiology at the University of California Los Angeles School of Medicine, has won the 1998 Rhône-Poulenc science book prize for Guns, Germs and Steel: The Fates of Human Societies (Norton/Vintage; for a review see Nature 386, 339; 1997). This makes him the only author to have won the prize twice (his previous success was The Third Chimpanzee). What's more, Guns, Germs and Steel was also awarded this year's Pulitzer prize for general non-fiction (see Nature 392, 750; 1998). Other shortlisted authors for the $£ 10,000$ Rhône-Poulenc prize, which was announced last week at the Science Museum in London, were David Deutsch (The Fabric of Reality; Allen Lane, 1997), Richard Fortey (Life; Knopf), Ernst Mayr (This Is Biology; Belknap, 1997) and Simon Singh (Fermat's Last Theorem; Walker, 1997). sion the authors think that more than semantics is at issue.

Finally, and perhaps most important, they seem to confuse semantic and empirical issues. There are important empirical issues. For example, fascinating experiments by Michael Wade, Charles Goodnight and others show that selection between groups (and even between two-species communities) can be more effective than individual selection in producing change. Sober and Wilson describe these experiments, although they seem curiously uninterested in the underlying mechanisms. In discussing Wade's results they say only, in a footnote, "the reasons... are too technical to be treated in this book".

There follow two chapters concerned with the evolution of human societies. The emphasis is on the competition between human groups, and the role of social norms in guiding the behaviour of individual members of such groups. Because social norms can homogenize the behaviour of groups, the result is that such groups evolve properties ensuring group survival, just as individuals evolve traits ensuring individual survival. I found these chapters the most rewarding section of the book. The essential point is that higher-level entities (for example, individuals carrying many genes, or societies comprising many individuals) will evolve characteristics favouring the success of the group, provided there are processes that reduce within-group selection. In human groups, the most important such process is the homogenization of behaviour by social norms.

The final part of the book discusses human altruism and the motives that cause it. Do people help others because they think they will get pleasure from doing so (hedonism), or because they have an ultimate desire to help another (true altruism)? Sober and Wilson argue that evolutionary biology can shed light on this problem. They do not say that human traits that evolved by individual selection are hedonistic, and those that evolved by group selection are truly altruistic. Their argument is more subtle than that. They start by reviewing psychological and philosophical attacks on the question, and decide it has not been decisively answered. Their approach is to take a specific example, parental care, and argue that it increases biological fitness, and that the most effective proximate mechanism for generating parental care is altruism. It is a kind of reverse engineering argument. Such arguments are used in biology, but usually as a first step in a physiological investigation. For example, an effective proximate mechanism for bird migration would be a magnetic sense: this has led people to seek direct evidence for such a sense. It is a lot harder to seek direct evidence for mechanisms underlying true altruism. I am not really competent to judge this final part of the book; indeed, I am not sure I understood the distinction between hedonistic and altruistic motives for helping others in the first place.

This book should carry a health warning. Read critically, it will stimulate thought about important questions. Swallowed whole, its effects would be disastrous. John Maynard Smith is in the School of Biological Sciences, University of Sussex, Falmer, Brighton BN1 9QG, UK.

\section{New edition}

A second edition of John Maynard Smith's Evolutionary Genetics has recently been published by Oxford University Press ( $£ 50$, \$95, hbk; $\mathfrak{1} 19.95, \$ 39.95$, pbk). When the first edition was reviewed in Nature 339, 107 (1989), R. C. Lewontin wrote: "When... a specialized subject is treated by an expert... the changes in the intellectual structure, the problems and the methods of the field can be seen. John Maynard Smith's new book is a model example."

\section{Per ardua ad Stockholm}

\section{Wish l'd Made You Angry Earlier: Essays on Science, Scientists, and Humanity \\ by Max Perutz \\ Cold Spring Harbor Laboratory Press: 1998. Pp. 354. $\$ 39$}

\section{Walter Gratzer}

Speaking at a memorial symposium for A. Michelson, Einstein related the following anecdote: he had, he said, once asked Michelson why, when the velocity of light was already known with adequate precision, he was continuing to measure it with ever greater accuracy. "Because," Michelson had replied, "I get so much fun out of it". "Das finde ich wunderbar," was Einstein's verdict.

The parallel to Max Perutz's 60-year devotion to the red protein, haemoglobin, is not exact of course, for the deeper he has dug into its workings, the more rewarding the lessons that have emerged, and his work stands now as one of the pinnacles of this century's achievements. The pleasure he has drawn from his quest shines through this lifeaffirming selection of his writings, and he quotes with approval Noël Coward's dictum: "Work is fun. There is no fun like work."

The centrepiece of this collection is Perutz's account of his experiences during the Second World War, when, in the company of thousands of desperate refugees from the horrors unfolding in Germany, and of Italian chefs and waiters who had lived peaceably in Britain for decades, he was incarcerated on the Isle of Man and then deported to Canada. The ageing blimp who commanded the camp was heard to remark that he had had no idea so many of these 